\title{
Phytoremediation of Oil-Contaminated Soils by Combining Flowering Plant Cultivation and Inoculation with Acinetobacter junii Strain M-2
}

\author{
Takamitsu Kai1 ${ }^{1}$ Yu Okamoto², Shuichiro Murakami², Masahiko Tamaki ${ }^{2 *}$ \\ ${ }^{1}$ Kurokawa Field Science Center, Meiji University, Kawasaki, Japan \\ ${ }^{2}$ School of Agriculture, Meiji University, Kawasaki, Japan \\ Email: ^mtamaki@meiji.ac.jp
}

How to cite this paper: Kai, T., Okamoto, Y., Murakami, S. and Tamaki, M. (2020) Phytoremediation of Oil-Contaminated Soils by Combining Flowering Plant Cultivation and Inoculation with Acinetobacter junii Strain M-2. Journal of Agricultural Chemistry and Environment, 9, 107-120. https://doi.org/10.4236/jacen.2020.93010

Received: June 18, 2020

Accepted: August 9, 2020

Published: August 12, 2020

Copyright $\odot 2020$ by author(s) and Scientific Research Publishing Inc. This work is licensed under the Creative Commons Attribution International License (CC BY 4.0).

http://creativecommons.org/licenses/by/4.0/ (c) (i) Open Access

\begin{abstract}
Oil contamination of the soil by petroleum products has become an enormous environmental problem. In this study, we examined whether remediation of oil-contaminated soils by cultivating three flowering plants (Mimosa, Gazania, and Zinnia) could be enhanced by inoculation with Acinetobacter junii strain M-2 at different plant growth stages (at sowing, at early growth, and at mid-growth). The growth of Zinnia cultivated in oil-contaminated soils inoculated at sowing was significantly superior to that in the non-inoculated soil. Although total petroleum hydrocarbon concentrations in soils inoculated at sowing were nominally lower than those in non-inoculated soils, especially in the case of Zinnia planting, the effect did not reach statistical significance. However, dehydrogenase activity was significantly higher in the soils inoculated with $A$. junii strain M-2 than in non-inoculated soils for all three plant species tested. These results demonstrate that a combination of ornamental plant cultivation (particularly Zinnia) and inoculation with $A$. junii strain M-2 increases the efficiency of oil-contaminated soil phytoremediation.
\end{abstract}

\section{Keywords}

Phytoremediation, Zinnia, Acinetobacter junii Strain M-2, Total Petroleum Hydrocarbon, Dehydrogenase Activity

\section{Introduction}

Petroleum products are used for many purposes, e.g., as fuel for cars and heaters, and as lubricants of mechanical parts, so they are essential for daily life in most societies. There are many known incidents when soils have become contaminated with these oils, and it is likely that many more areas of oil-contaminated 
soils will be discovered in the future [1] Soil and groundwater pollution adversely affect human health and the environment. Furthermore, it may also negatively impact land deals and other economic processes [2] [3] [4] [5]. Given the seriousness of these issues, in 2006, the Ministry of the Environment of Japan issued guidelines to prevent oil pollution which stipulate methods to counter soil contamination by oil [6]. Contaminated soils in Japan are often found and treated at locations adjacent to urban areas, which is in contrast to the situation in the majority of oil-producing countries. In urban areas, it is desirable to use ornamental flowering plants for the phytoremediation of contaminated soils. Ornamental plants have various advantages for remediation, as they also improve landscapes and have high aesthetic value. Various phytoremediation measures involving ornamental plants have been used to clean up oil-contaminated soils throughout the world [7] [8]. The use of the ornamental plant Mirabilis jalapa for the phytoremediation of oil-contaminated soils has been described previously [9] [10]. In particular, Peng et al. [10] grew plants for 127 days in soils contaminated with total petroleum hydrocarbons (TPH) at total concentrations of up to $10,000 \mathrm{mg} / \mathrm{kg}$. They found that TPH concentrations decreased significantly faster in soils with plants than in soils without plants. Furthermore, growth rates of plants in contaminated soils were similar to those of plants grown in uncontaminated soils. Zhang et al. [11] grew Impatiens balsamina in oil-contaminated soil for 120 days and found that this plant species promoted the decomposition of persistent organic petroleum hydrocarbons, such as resin and asphaltene. Bordoloi et al. [12] grew Axonopus compressus for 360 days in oil-contaminated soils and found that the addition of fertilizer enhanced both plant growth and remediation effects; the TPH level was reduced by $70 \%$ in fertilized soils compared to a $40 \%$ reduction in unfertilized-soils. Therefore, these results indicate that optimizing soil fertility by applying fertilizer also may enhance phytoremediation effects.

Studies that have used ornamental flowering plants for phytoremediation in Japan are rare. Of 33 ornamental plant species that grow well under Japanese environmental conditions, 3 species (Mimosa pudica, Gazania rigens, and Zinnia profusion) are known to grow well in oil-contaminated soil and have a remediation effect. In particular, species belonging to the genus Zinnia are the most effective for the phytoremediation of oil-contaminated soils [13]. In this study, among the four Zinnia species that we tested (Z. elegans, $Z$. angustifolia, $Z$. haageana, and $Z$. hybrida), we found that $Z$. hybrida was best suited to remediate contaminated soils. In addition, we found that "Profusion White" variety of $Z$. hybrida showed the highest growth and remediation rates in oil-contaminated soils [14]. Furthermore, we showed that phytoremediation of soils with higher levels of oil contamination could be enhanced by amending the soil with perlite and higher basal fertilizer levels [15]. Therefore, in such modified conditions, $Z$. hybrida "Profusion White" could be more effective over a wider range of areas. 
To further increase the phytoremediation capacity of Zinnia in oil-contaminated soils, we decided to examine the effects of inoculating rhizosphere soils with Acinetobacter junii strain M-2. Acinetobacter is a genus of gram-negative eubacteria that prefers wet environments, such as soil, and it is distributed widely in different environments. $A$. junii strain M-2 has been shown to be harmless to humans and plants [16] [17] isolated the $A$. junii strain M-2 from oil-contaminated soil in California, but their studies did not show whether this strain reduced TPH concentrations in the soil. Therefore, in this study, we investigated the effect of inoculation with $A$. junii M-2 on phytoremediation effects of three flowering plants, Mimosa, Gazania, and Zinnia in oil-contaminated soils.

\section{Materials and Methods}

\subsection{Isolation of Acinetobacter junii M-2}

One gram of rhizosphere soil around the roots of a Zinnia "Profusion White" plant was mixed with diesel oil. The soil suspension $(0.1 \mathrm{~mL})$ was added to the diesel oil medium $\left(\mathrm{KH}_{2} \mathrm{PO}_{4}: 0.3 \mathrm{~g}, \mathrm{Na}_{2} \mathrm{HPO}_{4} \cdot 12 \mathrm{H}_{2} \mathrm{O}: 1.4 \mathrm{~g}, \mathrm{NaCl}: 0.05\right.$ g, yeast extract: $0.01 \mathrm{~g}, \mathrm{NH}_{4} \mathrm{NO}_{3}: 0.02 \mathrm{~g}, \mathrm{FeSO}_{4} \cdot 7 \mathrm{H}_{2} \mathrm{O}: 0.04 \mathrm{~g}, \mathrm{MgSO}_{4} \cdot 7 \mathrm{H}_{2} \mathrm{O}: 0.014 \mathrm{~g}, \mathrm{Cu}$ $\mathrm{SO}_{4} \cdot 5 \mathrm{H}_{2} \mathrm{O}: 0.014 \mathrm{mg}, \mathrm{ZnCl}_{2}: 0.014 \mathrm{mg}, \mathrm{ScCl}_{3} \cdot 6 \mathrm{H}_{2} \mathrm{O}: 0.014 \mathrm{mg}, \mathrm{NiSO}_{4} \cdot 7 \mathrm{H}_{2} \mathrm{O}: 0.014$ $\mathrm{mg}, \mathrm{MnCl}_{2} \cdot 4 \mathrm{H}_{2} \mathrm{O}: 0.014 \mathrm{mg}, \mathrm{Na}_{2} \mathrm{WO}_{4} \cdot 2 \mathrm{H}_{2} \mathrm{O}: 0.014 \mathrm{mg}, \mathrm{SrSO}_{4}: 0.014 \mathrm{mg}$, $\mathrm{Na}_{2} \mathrm{~B}_{4} \mathrm{O}_{7} \cdot 10 \mathrm{H}_{2} \mathrm{O}: 0.014 \mathrm{mg},\left(\mathrm{CH}_{3} \mathrm{COO}\right)_{2} \mathrm{Co} \cdot 4 \mathrm{H}_{2} \mathrm{O}: 0.014 \mathrm{mg}, \mathrm{Na}_{2} \mathrm{MoO}_{4} \cdot 2 \mathrm{H}_{2} \mathrm{O}$ : $0.014 \mathrm{mg}, \mathrm{CaCl}_{2} \cdot 2 \mathrm{H}_{2} \mathrm{O}: 0.014 \mathrm{mg}, \mathrm{pH}=7.1,0.8 \%$ diesel in $\mathrm{H}_{2} \mathrm{O}: 7 \mathrm{~mL}$ ), and cultivated at $30^{\circ} \mathrm{C}$ and $130 \mathrm{rpm}$ with shaking for 2 days. The appropriately-diluted culture was spread on an LB plate [18] and cultivated at $30^{\circ} \mathrm{C}$ to obtain single colonies. Single colonies were transferred on LB slants. After checking growth of isolates, strain M-2, showing good growth, was selected for further experiments. A partial 16S rDNA fragment (about $1.5 \mathrm{~kb}$ ) was amplified by PCR [19] using a cell suspension of strain M-2 as a template. The amplified fragment was cloned and sequenced as described previously [20] [21]. The determined sequence was searched at the DNA database of the DNA Data Bank of Japan (www.ddbj.nig.ac.jp/index-j.html) using a Blast program. As a result, strain M-2 was identified as Acinetobacter junii based on the highest identity of reference strains.

\subsection{Preparation of Oil-Contaminated Soil}

Kanto loam soil from the Kurokawa Experimental Field at the Meiji University in Japan was air-dried in a greenhouse until its moisture content was below $1 \%$ $(\mathrm{w} / \mathrm{w})$. Then, soil specimens were sterilized in an autoclave at $120^{\circ} \mathrm{C}$ for $20 \mathrm{~min}$. Diesel oil was sprayed gradually with a pump sprayer while stirring the soil at 32 rpm with a soil mixer in a closed greenhouse to ensure even mixing. The contaminated soil was stirred once every 2 days in a closed greenhouse for 14 days, and then the remaining oil particles were volatilized [22]. The initial TPH concentration in the contaminated soil after volatilization was analyzed using a gas chromatograph hydrogen flame ionization detector (GC-17A GC-FID, Shimad- 
zu Corp. Ltd., Kyoto, Japan). A commercial solid fertilizer $\left(\mathrm{N}: \mathrm{P}_{2} \mathrm{O}_{5}: \mathrm{K}_{2} \mathrm{O}=10: 9: 8\right)$ was added to the oil-contaminated soil at a concentration of $0.2 \mathrm{~g} / \mathrm{L}$.

\subsection{Experiment 1: Effect of the Timing of the Inoculation with Acinetobacter junii Strain M-2 on Plant Growth and Phytoremediation Effects}

We investigated the phytoremediation effects of three flowering plants; Mimosa, Gazania, and Zinnia. Oil-contaminated soil samples (300 g each, initial TPH concentration: $14,414 \mathrm{mg}$ diesel/kg soil) containing basal fertilizer were placed in vinyl pots $(\varphi 200 \times 200 \mathrm{~mm})$. Eight seeds were planted in each pot and thinned to 5 individual plants per pot. Growth tests were conducted for 90 days in a growth chamber (MLR-351H, Sanyo Electric Corp. Ltd., Osaka, Japan) under 14 $\mathrm{h}$ light $/ 10 \mathrm{~h}$ dark conditions at $25^{\circ} \mathrm{C}, 80 \%$ relative humidity, and a photosynthetic photon flux density of $250 \mu \mathrm{mol} / \mathrm{m}^{2} \cdot \mathrm{s}$. Every 2 - 3 days, the pots were irrigated with $50 \mathrm{~mL}$ of water, which was sufficient to keep the soil surface moist, while avoiding any run-off from the pots. A commercial liquid fertilizer $\left(\mathrm{N}: \mathrm{P}_{2} \mathrm{O}_{5}: \mathrm{K}_{2} \mathrm{O}=6: 10: 5\right)$ was provided once per week instead of water $(50 \mathrm{~mL}$ of the 500 -fold diluted fertilizer). The soil surface was inoculated with $5 \mathrm{~mL}$ of cell suspension of $A$. junii strain M-2 $\left(1.0 \times 10^{9}\right.$ cells $\left./ \mathrm{mL}\right)$. Four treatment groups were set up to study the effect of the timing of inoculation with $A$. junii M-2: 1) at sowing (sowing); 2) 1 month after sowing (early-growth); 3) 2 months after sowing (mid-growth); and 4) not inoculated (non-inoculated). Five pots per treatment group were used. The experiment was done in a factorial design with five plants per pot. At 90 days after sowing (DAS), TPH concentrations and soil dehydrogenase activity (DHA) values were determined. In addition, the height of the five plants in each pot was measured, giving 25 plant height measurements per treatment. All roots and shoots were harvested from each pot and roots were carefully washed in tap water. The total dry weights of shoots and roots in each pot were measured after oven drying at $80^{\circ} \mathrm{C}$ for 3 days.

\subsection{Experiment 2: Effect of the Inoculation with A. junii Strain M-2 on Zinnia Plant Growth and Phytoremediation Effects}

Samples of oil-contaminated soil (200 g each, initial TPH concentration: 13,434 $\mathrm{mg}$ diesel/kg soil) and uncontaminated soils containing basal fertilizer were placed in vinyl pots $(\varphi 100 \times 120 \mathrm{~mm})$. Only Zinnia plants were used in Experiment 2. Eight seeds were planted in each pot and then thinned to 5 individual plants per pot. Growth tests were conducted in a growth chamber (MLR-351H, Sanyo Electric Corp. Ltd., Osaka, Japan) under the same conditions as in Experiment 1 . The soil surface was inoculated with $5 \mathrm{~mL}$ of cell suspension of $A$. junii M-2 $\left(1.0 \times 10^{9}\right.$ cells $\left./ \mathrm{mL}\right)$ at sowing. The experiment was done in a factorial design with five plants per pot and included both oil-contaminated and uncontaminated soils in which plants were grown or not grown. In experiments with contaminated soils, the following groups were examined: planted + inoculated (P-I plot); planted + not inoculated $(\mathrm{P}-\mathrm{NI}$ plot), not planted + inoculated (NP-I 
plot), not planted + not inoculated (NP-NI plot), not planted + not inoculated + not irrigated (D plot). Treatments for uncontaminated soils were as follows: planted + inoculated (NC-P-I plot) and planted + not inoculated (NC-P-NI plot). All pots except for those in the $\mathrm{D}$ plot were irrigated with $30 \mathrm{~mL}$ of water every 2 - 3 days, which was sufficient to keep the soil surface moist, while avoiding any run-off from the pot. A commercial liquid fertilizer $\left(\mathrm{N}: \mathrm{P}_{2} \mathrm{O}_{5}: \mathrm{K}_{2} \mathrm{O}=\right.$ 6:10:5) was applied weekly, instead of water $(30 \mathrm{~mL}$ of the 500 -fold diluted fertilizer). In total, 15 pots per treatment were used. At 45, 90, and 135 DAS, five pots per treatment were selected randomly for the analysis described below. TPH concentrations and soil DHA were measured. The height of five plants in each pot was measured, giving 25 plant height measurements per treatment. All roots and shoots were harvested from each pot and roots were washed carefully. The total dry weights of shoots and roots in each pot were measured after oven drying at $80^{\circ} \mathrm{C}$ for 3 days.

\subsection{Analysis of Soil TPH Concentration}

TPH levels were measured according to the guidelines issued by the Ministry of the Environment of Japan for preventing oil pollution in 2006 [23]. After removing the plant roots from each pot (apart from those in the unplanted group), the soil was mixed, and $30 \mathrm{~g}$ of it was dried at $30^{\circ} \mathrm{C}$ for 4 days. A soil sample ( 5 g) was then placed in a $50 \mathrm{~mL}$ conical flask with $15 \mathrm{~mL}$ of carbon disulfide, and the mixture was shaken for $30 \mathrm{~min}$. The supernatant was separated from the residue $2 \mathrm{~h}$ after shaking. Then, $15 \mathrm{~mL}$ of carbon disulfide was added to the residue, the mixture was shaken for $30 \mathrm{~min}$, and the supernatant was separated $1 \mathrm{~h}$ after shaking. This process was repeated one more time, and the three supernatants were combined. The recovered supernatants were diluted to $50 \mathrm{~mL}$ and filtered through a $0.45-\mu \mathrm{m}$ filter. Then, $1 \mu \mathrm{L}$ of the filtrate was injected into a gas chromatograph hydrogen flame ionization detector (GC-FID, GC-2010, Shimadzu Corp. Ltd., Kyoto, Japan) for analysis. The gas chromatography system was equipped with an Intercap IMS capillary column (liquid phase, 5\% phenylmethyl silicon, $30 \mathrm{~m} \times 0.32 \mathrm{~mm}$ internal diameter, $0.25-\mu \mathrm{m}$ film thickness; GL Science Inc., Japan) and a flame ionization detector. The injection and detector temperatures were both $320^{\circ} \mathrm{C}$. The heating program was set to maintain $35^{\circ} \mathrm{C}$ for $5 \mathrm{~min}$ and then increased to $320^{\circ} \mathrm{C}$ at a rate of $10^{\circ} \mathrm{C} / \mathrm{min}$. Helium was used as the carrier gas in the splitless mode. The analysis was repeated three times for each sample.

\subsection{Analysis of Soil DHA Level}

The soil DHA level was determined according to the method of [24] Plant roots were removed from the pots in which plants were grown (apart from those in the unplanted group). The soil from each pot was stirred, and a $30 \mathrm{~g}$ soil sample was transferred to a $100 \mathrm{~mL}$ test tube. Next, $1.0 \mathrm{~mL}$ of $0.25 \mathrm{mmol}$ Tris-hydrochloric buffer solution ( $\mathrm{pH}$ 6.8), $200 \mu \mathrm{L}$ of 0.4\% 2-(4-iodophenyl)-3-(4-nitrophenyl)-5phenyl tetrazolium chloride (INT), and $50 \mu \mathrm{L}$ of $1 \%$ glucose were added per $1 \mathrm{~g}$ 
of soil. The mixture was sealed tightly and incubated for $24 \mathrm{~h}$ in the dark at $30^{\circ} \mathrm{C}$. Methanol $(10 \mathrm{~mL})$ was added to stop the enzyme reaction, and the mixture was stirred for $1 \mathrm{~min}$ using a vortex mixer. The mixture was allowed to settle for 10 - $15 \mathrm{~min}$, and then, the supernatant was filtered. Approximately $4 \mathrm{~mL}$ of filtrate was analyzed using a spectrophotometer (UV-1700, Shimadzu Corp., Ltd., Kyoto, Japan) at a wavelength of $485 \mathrm{~nm}$, and the rate of conversion of INT to iodonitrotetrazolium formazan was determined. Each filtrate was measured three times.

\subsection{Statistical Analysis}

Data are presented as mean \pm SD values per groups of five pots and analyzed using Excel Statistics 2012 for Windows (Social Survey Research Information Co., Ltd., Tokyo, Japan). All data were analyzed by using one-way analysis of variance followed by the Fisher's least significant difference test, where appropriate. All statistical analyses were conducted with a significance level of $\alpha=0.05$ ( $P$ $<0.05)$.

\section{Results}

\subsection{Experiment 1: Effects of the Timing of Inoculation with Acinetobacter junii M-2 Strain on Plant Growth and Phytoremediation Effects}

\subsubsection{Effects of Inoculation Timing on Plant Growth}

The effects of the timing of inoculation with $A$. junii M-2 on plant height as well as shoot and root dry weights at 90 DAS are shown in Table 1. In Mimosa, inoculation timing did not have a significant effect on plant height. However, shoot and root dry weights were lower in all inoculated groups than those in the non-inoculated group. In Gazania, there was no significant effect of treatment on plant height either. The shoot and root dry weights in inoculated groups were heavier than those in the non-inoculated group. Plant height of Zinnia was shorter in groups inoculated during early- and mid-growth than that in the non-inoculated group. However, in the group inoculated at sowing, Zinnia plant height was about 1.3 times taller than that in the non-inoculated group. Furthermore, the shoot and root dry weights in the sowing treatment group were significantly heavier than those in the non-inoculated group. Thus, inoculation

Table 1. Influence of inoculation timing on plant growth.

\begin{tabular}{|c|c|c|c|c|c|c|c|c|c|c|c|c|}
\hline \multirow[b]{2}{*}{ Plant } & \multicolumn{4}{|c|}{ Plant height $(\mathrm{cm})$} & \multicolumn{4}{|c|}{ Shoot dry weight $(\mathrm{mg} /$ pot $\pm \mathrm{SD})$} & \multicolumn{4}{|c|}{ Root dry weight $(\mathrm{mg} /$ pot $\pm \mathrm{SD})$} \\
\hline & Seeding & $\begin{array}{c}\text { Early } \\
\text { growth }\end{array}$ & $\begin{array}{c}\text { Mid } \\
\text { growth }\end{array}$ & Non-inoculated & Seeding & $\begin{array}{c}\text { Early } \\
\text { growth }\end{array}$ & $\begin{array}{c}\text { Mid } \\
\text { growth }\end{array}$ & Non-inoculated & Seeding & $\begin{array}{c}\text { Early } \\
\text { growth }\end{array}$ & $\begin{array}{c}\text { Mid } \\
\text { growth }\end{array}$ & Non-inoculated \\
\hline Mimosa & $20.90 \mathrm{a}^{\mathrm{Z}}$ & $18.90 \mathrm{a}$ & $19.20 \mathrm{a}$ & $20.32 \mathrm{a}$ & $0.41 \mathrm{a}$ & $0.65 \mathrm{a}$ & $0.56 \mathrm{a}$ & $0.65 \mathrm{a}$ & $0.24 \mathrm{a}$ & $0.28 \mathrm{a}$ & $0.24 \mathrm{a}$ & $0.33 \mathrm{a}$ \\
\hline Gazania & $15.20 \mathrm{a}$ & $14.60 \mathrm{a}$ & $16.70 \mathrm{a}$ & $15.67 \mathrm{a}$ & $0.86 \mathrm{a}$ & $0.84 \mathrm{a}$ & $0.86 \mathrm{a}$ & $0.74 \mathrm{a}$ & $0.21 \mathrm{a}$ & $0.31 \mathrm{a}$ & $0.30 \mathrm{a}$ & $0.25 \mathrm{a}$ \\
\hline Zinnia & $21.97 \mathrm{a}$ & $15.83 \mathrm{a}$ & $11.63 \mathrm{a}$ & $16.83 \mathrm{a}$ & $1.41 \mathrm{a}$ & $0.95 \mathrm{a}$ & $0.88 \mathrm{a}$ & $0.70 \mathrm{a}$ & $0.38 \mathrm{a}$ & $0.27 \mathrm{a}$ & $0.24 \mathrm{a}$ & $0.11 \mathrm{a}$ \\
\hline
\end{tabular}

${ }^{\mathrm{Z}}$ Values marked by distinct letters in inoculated and non-inoculated groups are significantly different at the $5 \%$ level of probability based on the Fisher's least significant difference test (plant height: $n=25$, shoot and root dry weights: $n=5$ ). 
of $A$. junii $M-2$ at sowing drastically improved Zinnia growth despite oil contamination of the soil.

\subsubsection{Influence of Inoculation Timing on Soil TPH Concentration}

There were no significant effects of inoculation timing on soil TPH concentrations in oil-contaminated soils planted with Mimosa, Gazania, or Zinnia (Figure 1). However, soil TPH concentrations in all treatment groups were significantly lower than the initial soil TPH concentration. In addition, soil TPH concentrations of inoculated groups were lower than those of non-inoculated groups for all three plants. TPH concentrations in the groups inoculated at sowing treatment were nominally lower than in the groups inoculated at other points. Furthermore, among the groups inoculated at sowing, the lowest TPH concentration was observed in Zinnia.

\subsubsection{Influence of Inoculation Timing on Soil DHA Levels}

Soil DHA levels were significantly higher in inoculated groups than in non-inoculated groups for all three plant species (Figure 2). In particular, for Zinnia, soil DHA levels at sowing, early-growth, and mid-growth inoculated treatments were $18.3,18.1$, and $16.3 \mathrm{mg}$ formazan/g of soil, respectively. Soil DHA levels for Zinnia groups inoculated at sowing and at early growth were higher than that in the mid-growth group. However, there were no effects of inoculation timing on soil DHA levels in soils with cultivated Mimosa or Gazania. There was a slightly higher soil DHA level at sowing in the Zinnia inoculated group (18.3 mg formazan/g soil) compared to those in Mimosa and Gazania groups (17.4 and $17.0 \mathrm{mg}$ formazan/g soil, respectively), although this difference was not statistically significant. There was a strong negative correlation between soil TPH concentration and soil DHA level in planted, oil-contaminated soils.

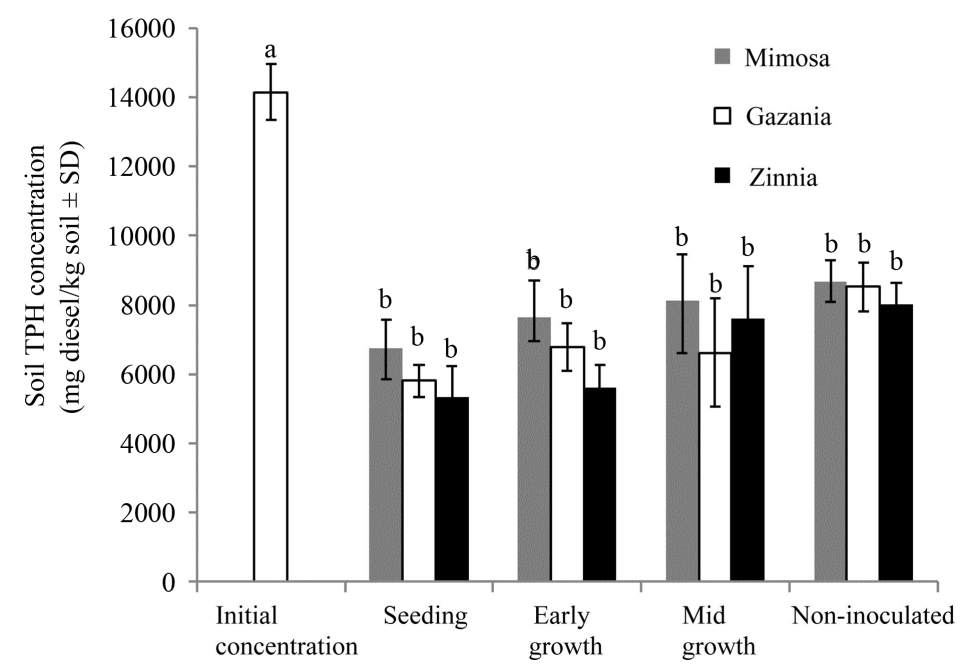

Figure 1. Influence of inoculation timing on total petroleum hydrocarbon (TPH) concentration in oil-contaminated soils with cultivated plants. ${ }^{\mathrm{z}}$ Values marked by distinct letters are significantly different at the $5 \%$ level of probability based on the Fisher's least significant difference test $(n=5)$. 


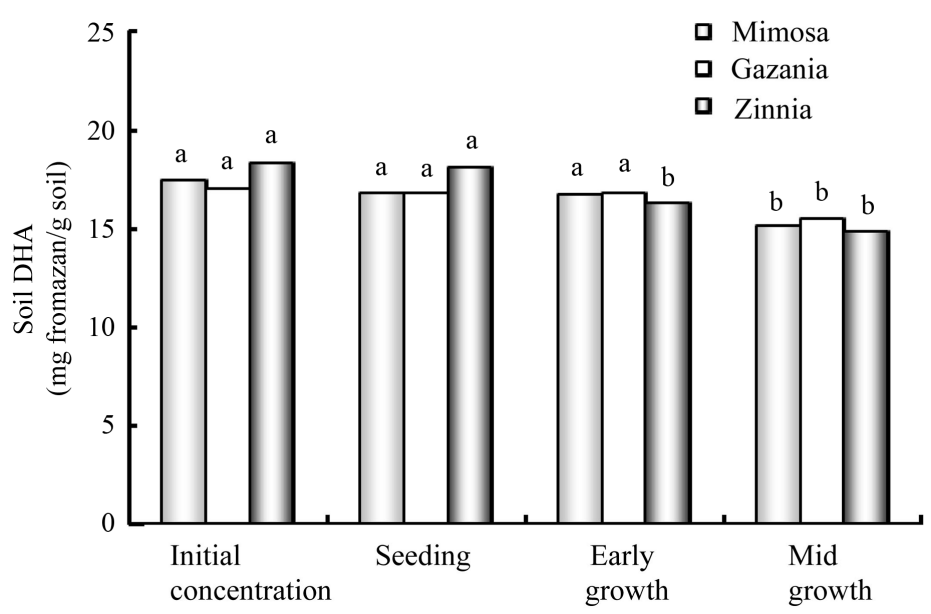

Figure 2. Influence of inoculation timing on the level of dehydrogenase activity (DHA) in oil-contaminated soils with cultivated plants. ${ }^{\mathrm{Z}}$ Values marked by distinct letters are significantly different at the $5 \%$ level of probability based on the Fisher's least significant difference test $(n=5)$.

\subsection{Experiment 2: Impact of Inoculation with Acinetobacter junii Strain M-2 on Zinnia Plant Growth and Phytoremediation Effects}

\subsubsection{Influence of Inoculation on Zinnia Growth}

Zinnia plant height in oil-contaminated soils (P-I and P-NI plots) at 45 DAS was significantly lower than that in non-contaminated soils (NC-P-I and NC-P-NI plots), but at 90 and 135 DAS there were no differences in plant height among all plots (Table 2). Inoculation with $A$. junii M-2 did not affect plant height. However, the shoot and root dry weights in the inoculated NC-P-I and P-I plots were heavier than those in the non-inoculated NC-P-NI and P-NI plots throughout the 135-day growing period.

\subsubsection{Influence of Inoculation on Soil TPH Concentration}

Inoculation with $A$. junii M-2 did not significantly affect soil TPH concentrations at 45 and 90 DAS (Figure 3). Soil TPH concentration of the plots with cultivated Zinnia plants (P-I and P-NI plots) was significantly lower than that in the plots without Zinnia plants (NP-I, NP-NI, and D plots) at 135 DAS. In addition, the soil TPH concentration of the plot with Zinnia plants and inoculated with $A$. junii M-2 (P-I plot) was lower than those in other plots (P-NI, NP-I, NP-NI, and D plots) at 45,90 , and 135 DAS.

\subsubsection{Influence of Inoculation on Soil DHA Level}

Soil DHA levels in the oil-contaminated soils (P-I, P-NI, NP-I, and NP-NI plots) were higher than those in the non-contaminated soils (NC-P-I and NC-P-NI plots) at 45, 90, and 135 DAS (Figure 4). Furthermore, soil DHA levels in the plots with planted Zinnia (P-I and P-NI plots) were higher than those in the plots without plants in oil-contaminated soil (NP-I and NP-NI plots) at 90 and 135 DAS. The soil DHA level decreased significantly at 135 DAS in all plots. The 


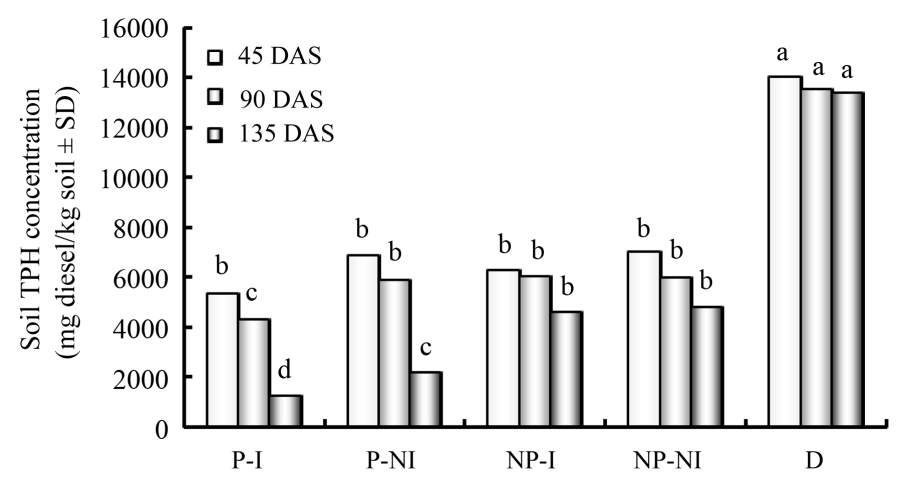

Figure 3. Influence of inoculation with $A$. junii strain M-2 on total petroleum hydrocarbon $(\mathrm{TPH})$ concentration at different days after sowing (DAS; $n=5$ ). P-I: planted + inoculated in contaminated soil. P-NI: planted + not inoculated in contaminated soil. NP-I: not planted + inoculated in contaminated soil. NP-NI: not planted + not inoculated in contaminated soil. D: not planted + not inoculated + not irrigated in contaminated soil. ${ }^{\mathrm{Z}}$ Values marked by different letters are significantly different at the $5 \%$ level of probability based on the Fisher's least significant difference test.

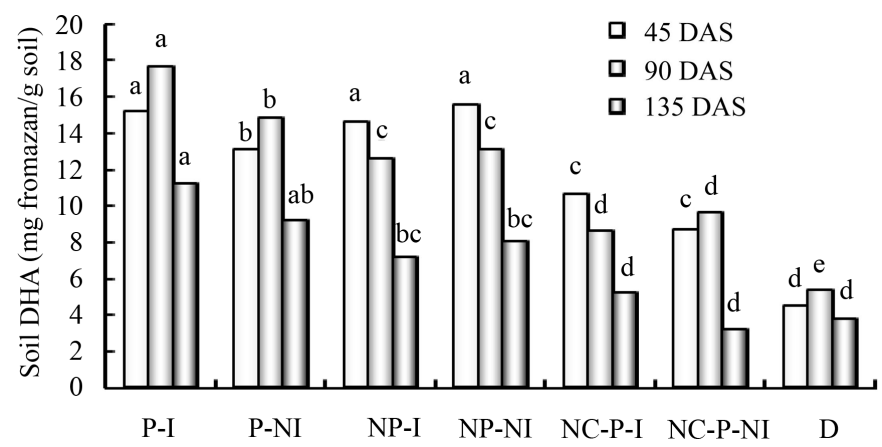

Figure 4. Influence of inoculation with $A$. junii strain M-2 on soil dehydrogenase activity (DHA; $n=5)$. P-I: planted + inoculated in contaminated soil. P-NI: planted + not inoculated in contaminated soil. NP-I: not planted + inoculated in contaminated soil. NP-NI: not planted + not inoculated in contaminated soil. NC-P-I: planted + inoculated in uncontaminated soil. NC-P-NI: planted + not inoculated in uncontaminated soil. D: not planted + not inoculated + not irrigated in contaminated soil. ${ }^{\mathrm{Z}}$ Values marked by distinct letters are significantly different at the $5 \%$ level of probability based on the Fisher's least significant difference test.

Table 2. Influence of inoculation with $A$. junii strain M-2 on plant growth.

\begin{tabular}{cccccccccc}
\hline & \multicolumn{3}{c}{ Plant height $(\mathrm{cm} \pm \mathrm{SD})$} & \multicolumn{2}{c}{ Shoot dry weight $(\mathrm{mg} /$ pot $\pm \mathrm{SD})$} & \multicolumn{3}{c}{ Root dry weight $(\mathrm{mg} /$ pot \pm SD) } \\
\cline { 2 - 10 } Treatments $^{\mathrm{z}}$ & \multicolumn{2}{c}{ Days after seeding (DAS) } & \multicolumn{2}{c}{ Days after seeding (DAS) } & \multicolumn{2}{c}{ Days after seeding (DAS) } \\
\cline { 2 - 10 } & 45 & 90 & 135 & 45 & 90 & 135 & 45 & 90 & 135 \\
\hline NC-P-I & $9.6 \mathrm{a}^{\mathrm{y}}$ & $15.2 \mathrm{a}$ & $21.9 \mathrm{a}$ & $0.097 \mathrm{a}^{\mathrm{y}}$ & $1.777 \mathrm{a}$ & $4.330 \mathrm{a}$ & $0.072 \mathrm{a}^{\mathrm{y}}$ & $0.267 \mathrm{a}$ & $0.643 \mathrm{a}$ \\
NC-P & $9.9 \mathrm{a}$ & $15.6 \mathrm{a}$ & $22.7 \mathrm{a}$ & $0.063 \mathrm{~b}$ & $1.428 \mathrm{~b}$ & $3.640 \mathrm{~b}$ & $0.028 \mathrm{~b}$ & $0.259 \mathrm{a}$ & $0.493 \mathrm{abc}$ \\
P-I & $6.6 \mathrm{~b}$ & $16.3 \mathrm{a}$ & $21.4 \mathrm{a}$ & $0.024 \mathrm{c}$ & $1.007 \mathrm{c}$ & $3.313 \mathrm{~b}$ & $0.011 \mathrm{bc}$ & $0.218 \mathrm{a}$ & $0.550 \mathrm{ab}$ \\
P & $5.8 \mathrm{~b}$ & $13.5 \mathrm{~b}$ & $20.6 \mathrm{a}$ & $0.010 \mathrm{~d}$ & $0.859 \mathrm{c}$ & $2.723 \mathrm{c}$ & $0.001 \mathrm{c}$ & $0.139 \mathrm{a}$ & $0.320 \mathrm{c}$ \\
\hline
\end{tabular}

${ }^{y}$ Values marked by distinct letters at different time points are significantly different at the $5 \%$ level of probability based on the Fisher's least significant difference test (plant height: $n=25$, shoot and root dry weights: $n=5$ ). ${ }^{\mathrm{Z}}$ NC-P-I: planted + inoculated in non-contaminated soil. NC-P-NI: planted + not inoculated in non-contaminated soil. P-I: planted + inoculated in contaminated soil. P-NI: planted + not inoculated in contaminated soil. 
soil DHA level in P-I plot with cultivated Zinnia plants in oil-contaminated and inoculated soil was higher than those in all other plots throughout the 135-day growing period.

\section{Discussion}

In the present study, we sought to establish if the phytoremediation activity of ornamental plants in oil-contaminated soils could be enhanced further by the inoculation of the soil with a widely distributed Acinetobacter species. We found that Zinnia growth was greatly influenced by the inoculation of oil-contaminated soil surface with $A$. junii strain M-2. Plant height, shoot dry weight, and root dry weight were significantly higher upon inoculation at sowing. There were no significant effects of inoculation timing on TPH concentrations in the soils planted with Mimosa, Gazania, and Zinnia plants, although there was a greater tendency of lower TPH concentrations in the inoculated groups than in the non-inoculated groups, particularly, in the Zinnia group inoculated at sowing. In addition, soil DHA levels were higher in the inoculated groups than those in the non-inoculated groups, again, particularly in the Zinnia group inoculated at sowing.

In the previous studies, it is reported that many kinds of bacteria possess some alkane degrading pathways and can therefore utilize oils and alkanes [25]. Strains of Acinetobacter were reported to be excellent alkane degraders [26] [27]. For example, Acinetobacter sp. strain DSM 17874 can grow on $n$-alkanes ranging from decane $\left(\mathrm{C}_{10} \mathrm{H}_{22}\right)$ to tetracontane $\left(\mathrm{C}_{40} \mathrm{H}_{82}\right)$ as a sole carbon source [26]. Although we did not analyze the chain length of the residual diesel oil in soil samples after phytoremediation treatment using $A$. junii strain M-2, the oil-degrading ability of $A$. junii strain M-2 seems to be enough to remove the diesel oil contaminant.

Kubota et al. [28] reported that the amount of root exudations varies depending on plant species. When $A$. junii strain M-2 was isolated from the rhizosphere of cultivated Zinnia, it was found to populate the exudates of Zinnia roots. It appears that increased contact with both $A$. junii strain $\mathrm{M}-2$ and exudates from Zinnia roots potentiated Zinnia growth. Sun et al. [29] reported that the level of soil DHA and the number of bacteria in diesel-contaminated soil inoculated with Gordonia sp. S2RP-17 were significantly higher than that in non-inoculated contaminated soil. Jing et al. [30] reported that the level of soil DHA and the number of bacteria in the soil contaminated by polycyclic aromatic hydrocarbons were higher if it was planted with alfalfa than if it was in soil without this plant. In our experiments, soil DHA levels in the soils with planted cultivated Mimosa and Gazania were not affected by the timing of inoculation with $A$. junii strain M-2. Soil DHA levels in the inoculated groups were higher than those in the corresponding non-inoculated groups, but there was no significant relationship between the increase in soil DHA levels and inoculation timing. These observations suggest that $A$. junii M-2 might be more specific to Zinnia or that the exudates from the roots of Mimosa and Gazania do not promote substantial 
growth in either plant species.

Soil TPH concentration in the soils with cultivated Zinnia plants was lower than that in the soil without plants. In addition, TPH concentration was the lowest in the soil planted with Zinnia plants and inoculated with $A$. junii M-2. The combination of Zinnia planting and inoculation of the soil with $A$. junii M-2 enhanced phytoremediation of oil-contaminated soils. Additionally, the level of DHA in the soil planted with Zinnia plants and inoculated with $A$. junii M-2 was higher than that in all other treatment groups.

Root growth forms pores in the soil, improves water and air permeability [31], and promotes the contact of insoluble pollutants with soil particles and microorganisms [32]. Furthermore, the root surface is an ideal environment for the growth of microorganisms because root exudates provide abundant nutrients, such as carboxylic acids, amino acids, proteins, and sugars [33]. It has been previously shown that soil inoculation with oil-borne bacteria improves plant growth and enhances the remediation of soil polluted by oil. For example, Huang et al. [1] reported that Enterobacter cloacae strains UW4 and CAL2, which promoted plant growth, reduced TPH concentrations when they were inoculated into soils planted with Festuca arundinacea. In addition, Tang et al. [34] reported reductions of TPH concentrations in oil-contaminated soils when cotton (Gossypium hirsutum) was planted after the inoculation of plant growth promoting microorganisms, such as $A$. brasilence, $A$. radioresistens, or $R$. erythropolis. Furthermore, Sun et al. [29] reported that the growth of Zea mays L. and soil characteristics were improved after inoculation of oil-contaminated soil with Gordonia sp. strain S2RP-17. Therefore, these studies show that the combined use of a specific plant and a fungal microbial strain can improve the efficiency of phytoremediation. In our study, we demonstrated that using a combination of Zinnia plants and inoculation with $A$. junii M-2 improved remediation efficiency as indicated by lower TPH concentrations in oil-contaminated soils. $A$. junii strain M-2 likely promoted the stronger growth of Zinnia roots, thereby increasing the level of soil DHA and reducing TPH concentrations, compared to its effects in combination with other plants. This study shows that $A$. junii strain M-2 could be a promising microorganism for enhancing the phytoremediation of diesel-contaminated soils, particularly in combination with Zinnia plant cultivation.

\section{Conclusion}

This study showed that Acinetobacter junii strain M-2 enhanced the phytoremediation of oil-contaminated soils using Zinnia plants, when it was applied at sowing. This combined bacterial and phytoremediation approach is inexpensive and environmentally friendly. However, because sterilized soils were used in this study to examine phytoremediation effects, the $A$. junii strain M-2 could have been in an unnaturally favorable environment. Further studies should be conducted using unsterilized soils to validate the practical application of this treat- 
ment in more natural conditions.

\section{Conflicts of Interest}

The authors declare no conflicts of interest regarding the publication of this paper.

\section{References}

[1] Huang, X.D., El-Alawi, Y., Gurska, J., Glick, B.R. and Greenberg, B.M. (2005) A Multi-Process Phytoremediation System for Decontamination of Persistent Total Petroleum Hydrocarbon (TPHs) from Soil. Microchemistry Journal, 81, 139-147. https://doi.org/10.1016/j.microc.2005.01.009

[2] Hall, C., Tharakan, P., Hallock, J., Cleveland, C. and Jefferson, M. (2003) Hydrocarbons and the Evolution of Human Culture. Nature, 426, 318-322.

https://doi.org/10.1038/nature02130

[3] Peña-Castro, J.M., Barrera-Figueroa, B.E., Fernández-Linares, L., Ruiz-Medrano, R. and Xoconostle-Cázares, B. (2006) Isolation and Identification of Up-Regulated Genes in Bermudagrass Roots (Cynodon dactylon L.) Grown under Petroleum Hydrocarbon Stress. Plant Science, 170, 724-731. https://doi.org/10.1016/j.plantsci.2005.11.004

[4] Phillips, L.A., Greer, C.W. and Germida, J.J. (2006) Culture-Based and Culture-Independent Assessment of the Impact of Mixed and Single Plant Treatments on Rhizosphere Microbial Communities in Hydrocarbon Contaminated Flare-Pit Soil. Soil Biology and Biochemistry, 38, 2823-2833. https://doi.org/10.1016/j.copbio.2009.03.007

[5] Dowling, D.N. and Doty, S.L. (2009) Improving Phytoremediation through Biotechnology. Current Opinion in Biotechnology, 20, 204-206.

[6] Guideline for Soil Contamination Countermeasures. (2006) Guidelines for Oil Pollution Control by the Ministry of the Environment Corresponding to Oil Oils and Oil Film Problems by Oil-Containing Soil Chemical Industry Daily News Company 205.

[7] Chioma, B.C., Christopher, C.A. and Evan, M.F. (2017) Erratum to: Shift in Microbial Group during Remediation by Enhanced Natural Attenuation (RENA) of a Crude Oil-Impacted Soil: A Case Study of Ikarama Community, Bayelsa, Nigeria. Biotech, 7, Article No. 228. https://doi.org/10.1007/s13205-017-0867-6

[8] Eman, K. and Ball, A.S. (2017) Soil Bioremediation Approaches for Petroleum Hydrocarbon Polluted Environments. AIMS Microbiology, 3, 25-49. https://doi.org/10.3934/microbiol.2017.1.25

[9] Anderson, T.A., Guthrie, E.A. and Walton, B.T. (1993) Bioremediation in the Rhizosphere. Environmental Science \& Technology, 27, 2630-2636. https://doi.org/10.1021/es00049a001

[10] Peng, S., Zhou, Q. and Cai, Z. (2009) Phytoremediation of Petroleum Contaminated Soils by Mirabilis Jalapa L. in a Greenhouse Plot Experiment. Journal of Hazardous Materials, 168, 1490-1496. https://doi.org/10.1016/j.jhazmat.2009.03.036

[11] Zhang, C., Zhou, Q.X., Peng, S.W. and Kenan, L. (2010) Promoted Biodegradation and Microbiological Effects of Petroleum Hydrocarbons by Impatiens balsamina L. with Strong Endurance. Journal of Hazardous Materials, 183, 731-737. https://doi.org/10.1016/j.jhazmat.2010.07.087

[12] Bordoloi, S., Basumatary, B., Saikia, R. and Das, H.C. (2012) Axonopus com- 
pressus (Sw.) P. Beauv. A Native Grass Species for Phytoremediation of Hydrocarbon-Contaminated Soil in Assam, India. Journal of Chemical Technology \& Biotechnology, 87, 1335-1341. https://doi.org/10.1002/jctb.3765

[13] Ozawa, S., Ikeura, H., Kaimi, E. and Tamaki, M. (2014) Selection of the Most Effective Cultivar of Genus Zinnia Flowers for Phytoremediation of Oil-Contaminated Soil. International Journal of Plant \& Soil Science, 4, 61-71.

[14] Ikeura, H., Ozawa, S. and Tamaki, M. (2016) Varietal Differences in Zinnia Hybrid for Remediation in Oil-Contaminated Soil. Journal of International Scientific Publications. Ecology and Safety, 10, 265-272.

[15] Kai, T., Ikeura, H., Ozawa, S. Tamaki, M. (2019) Effects of Basal Fertilizer and Perlite Amendment on Growth of Zinnia and its Remediation Capacity in Oil-Contaminated Soils. International Journal of Phytoremediation, 20, 1236-1242. https://doi.org/10.1080/15226514.2018.1460310

[16] Arakawa, Y. (2010) Genus Acinetobacter. IASR, 31, 194.

[17] Fatima, M.B., Flavio, A., Oliveira, C., Benedict, C. and Okeke, W. and Frankenberger Jr., T.J. (2005) Diversity of Biosurfactant Producing Microorganisms Isolated from Soils Contaminated with Diesel Oil. Microbiological Research, 160, 249-255. https://doi.org/10.1016/j.micres.2004.08.005

[18] Sambrook, J. and Russell, D.W. (2001) Molecular Cloning a Laboratory Manual. 3rd Edition, Cold Spring Harbor Laboratory Press, Cold Spring Harbor, NY.

[19] Edwards, U., Rogall, T., Blöcker, H., Emde, M. and Böttger, E.C. (1989) Isolation and Direct Complete Nucleotide Determination of Entire Genes. Characterization of a Gene Coding for 16S Ribosomal RNA. Nucleic Acids Research, 17, 7843-7853. https://doi.org/10.1093/nar/17.19.7843

[20] Takahashi, Y., Nomura, M., Komiya, T., Goto, M. and Murakami, S. (2012) Screening of Lignocelluloce-Degrading Fungi from Gray Gentle Lemur (Hapalemur griseus) Feces. Bulletin of School of Agriculture, Meiji University, 61, 77-86.

[21] Takahashi, Y., Kawabata, H. and Murakami, S. (2013) Analysis of Functional Xylanases in Xylan Degradation by Aspergillus niger $\mathrm{E}_{-1}$ and Characterization of the $\mathrm{GH}$ Family 10 Xylanase XynVII. SpringerPlus, 2, Article No. 447. https://doi.org/10.1186/2193-1801-2-447

[22] The Geo-Environmental Protection Center (2006) The TPH Test Methods Using GC-FID, Guidelines against Oil Pollution by the Ministry of Environment. The Chemical Daily Co., Ltd., Tokyo, 99-115.

[23] Kaimi, E., Mukaidani, T., Miyoshi, S. and Tamaki, M. (2006) Ryegrass Enhancement of Biodegradation in Diesel-Contaminated Soil. Environmental and Experimental Botany, 55, 110-119. https://doi.org/10.1016/j.envexpbot.2004.10.005

[24] Hayase, K. (1992) Measurement of Enzyme Activity in Soil. Experimental Methods in Soil Microbiology-New Edition. Youken-dou, Tokyo, 356-357.

[25] Van Beilen, J.B., Li, Z., Duetz, W.A., Smits, T.H.M. and Witholt, B. (2003) Diversity of Alkane hydroxylase Systems in the Environment. Oil \& Gas Science and Technology, 58, 427-440. https://doi.org/10.2516/ogst:2003026

[26] Throne-Holst, M., Wentzel, A., Ellingsen, T.E, Kotlar, H.K. and Zotchev, S.B. (2007) Identification of Novel Genes Involved in Long-Chain n-Alkane Degradation by Acinetobacter sp. Strain DSM 17874. Applied and Environmental Microbiology, 73, 3327-3332. https://doi.org/10.1128/AEM.00064-07

[27] Liu, H., Yao, J., Yuan, Z., Shang, Y., Chen, H., Wang, F., Masakorala, K., Yu, C., Cai, 
M.M., Blake, R.E. and Choi, M.M.F. (2014) Isolation and Characterization of Crude-Oil-Degrading Bacteria from Oil-Water Mixture in Dagang Oilfield, China. International Biodeterioration \& Biodegradation, 87, 52-59.

https://doi.org/10.1016/j.ibiod.2013.11.005

[28] Kubota, M., Hyakumachi, M. and Miyazawa, M. (2004) Influence of Root Exudates from Cucumis sativus and Daucus carota on Arbuscular mycorrhizal Colonization. Journal of Oleo Science, 53, 207-210.

[29] Sun, H.H., Hee, W.R., Jaisoo, K. and Kyung, S.C. (2011) Rhizoremediation of Diesel-Contaminated Soil Using the Plant Growth-Promoting Rhizobacterium gordonia Sp. S2RP-17. Biodegradation, 22, 593-601. https://doi.org/10.1007/s10532-010-9432-2

[30] Zhang, J., Yin, R., Lin, X., Liu, W., Chen, R. and Li, X. (2010) Interactive Effect of Biosurfactant and Microorganism to Enhance Phytoremediation for Removal of Aged Polycyclic Aromatic Hydrocarbons from Contaminated Soils. Journal of Health Science, 563, 257-266.

[31] Singer, A.C., Smith, D., Jury, W.A., Hathuc, K. and Crowley, D.E. (2002) Impact of the Plant Rhizosphere and Augmentation on Remediation of Polychlorinated Biphenyl Contaminated Soil. Environmental Toxicology \& Chemistry, 22, 1998-2004. https://doi.org/10.1897/02-471

[32] Banks, M.K., Kulakow, P., Schwab, A.P., Chen, Z. and Rathbone, K. (2003) Degradation of Clued Oil in Soil the Rhizosphere of Sorghum bicolor. International Journal of Phytoremediation, 5, 225-234. https://doi.org/10.1080/713779222

[33] Kaimi, E., Mukaidani, T. and Tamaki, M. (2007) Effect of Rhizodegradation in Die Sel-Contaminated Soil under Different Soil Conditions. Plant Production Science, 10, 105-111. https://doi.org/10.1626/pps.10.105

[34] Tang, J.C., Wang, R.G., Niu, X.W., Wang, M., Chu, H.R. and Zhou, Q.X. (2010) Characterization of the Rhizoremediation of Petroleum-Contaminated Soil: Effect of Different Influencing Factors. Biogeosciences, 7, 3961-3969.

https://doi.org/10.5194/bg-7-3961-2010 